\title{
Resolving vorticity-driven lateral fire spread using the WRF-Fire coupled atmosphere-fire numerical model
}

\author{
C. C. Simpson ${ }^{1}$, J. J. Sharples ${ }^{1}$, and J. P. Evans ${ }^{2}$ \\ ${ }^{1}$ Applied and Industrial Mathematics Research Group, School of Physical, Environmental and Mathematical Sciences, \\ University of New South Wales, Canberra, Australia \\ ${ }^{2}$ ARC Centre of Excellence for Climate System Science and the Climate Change Research Centre, University of New South \\ Wales, Sydney, Australia \\ Correspondence to: C. C. Simpson (c.simpson@ adfa.edu.au)
}

Received: 21 March 2014 - Published in Nat. Hazards Earth Syst. Sci. Discuss.: 16 May 2014

Revised: - - Accepted: 23 July 2014 - Published: 5 September 2014

\begin{abstract}
Vorticity-driven lateral fire spread (VLS) is a form of dynamic fire behaviour, during which a wildland fire spreads rapidly across a steep leeward slope in a direction approximately transverse to the background winds. VLS is often accompanied by a downwind extension of the active flaming region and intense pyro-convection. In this study, the WRF-Fire (WRF stands for Weather Research and Forecasting) coupled atmosphere-fire model is used to examine the sensitivity of resolving VLS to both the horizontal and vertical grid spacing, and the fire-to-atmosphere coupling from within the model framework. The atmospheric horizontal and vertical grid spacing are varied between 25 and $90 \mathrm{~m}$, and the fire-to-atmosphere coupling is either enabled or disabled. At high spatial resolutions, the inclusion of fire-to-atmosphere coupling increases the upslope and lateral rate of spread by factors of up to 2.7 and 9.5, respectively. This increase in the upslope and lateral rate of spread diminishes at coarser spatial resolutions, and VLS is not modelled for a horizontal and vertical grid spacing of $90 \mathrm{~m}$. The lateral fire spread is driven by fire whirls formed due to an interaction between the background winds and the vertical circulation generated at the flank of the fire front as part of the pyro-convective updraft. The laterally advancing fire fronts become the dominant contributors to the extreme pyro-convection. The results presented in this study demonstrate that both high spatial resolution and two-way atmosphere-fire coupling are required to model VLS with WRF-Fire.
\end{abstract}

\section{Introduction}

Multi-scale physical interactions between a wildland fire and the local fire environment, namely the topography, the fuel and the weather (Countryman, 1972), can lead to dynamic fire behaviour and result in rapid fire growth. The dynamic escalation of wildland fires into conflagrations represents a major challenge in wildland fire management. Current operational fire spread models, a number of which are summarised in the recent review of wildland fire spread models by Sullivan (2009a, b, c), typically assume that the rate of spread will remain constant unless there is a change in the underlying fire environment conditions. This steady state assumption can be invalid for dynamic modes of fire spread, in which the rate of spread can vary markedly due to coupled interactions between a wildland fire and the surrounding fire environment. Understanding the physical processes that underpin these dynamic modes of fire spread is therefore a key step towards improving the planning, preparedness, response and recovery surrounding the incidence of extreme fires.

A number of dynamic modes of fire spread, in which the rate of spread can not be determined solely from the fire environment conditions, have now been identified. Wildland fires can exhibit a continually increasing rate of spread on steep slopes and in canyons (Viegas and Pita, 2004; Dold and Zinoviev, 2009; Pimont et al., 2012). Viegas et al. (2012) and Sharples et al. (2013b) discussed the abrupt increase in rate of spread that can occur when two wildland fires intersect at an oblique angle. Clark et al. (1996a, b) used the CAWFE (Coupled Atmosphere-Wildland Fire Environment) model to 
examine coupled atmosphere-fire interactions, such as dynamic fingering, in which rotating columns of air near the fire front can drive rapid fire spread ahead of the main front. Rotating columns of air above a wildland fire, commonly referred to as fire whirls when formed due to pyro-convection (Forthofer and Goodrick, 2011), are a common feature in dynamic modes of fire spread.

McRae (2004) and Sharples et al. (2012) identified an important driver of extreme fire development in the 2003 Canberra bushfires, which involved rapid lateral fire spread across a steep leeward slope in a direction approximately transverse to the background winds, in addition to the usual downwind direction. Originally termed "lee-slope channelling" and then "fire channelling", this dynamic mode of fire spread has subsequently been investigated through laboratory experiments (Sharples et al., 2010; Farinha, 2011) and coupled atmosphere-fire modelling (Simpson et al., 2013; Sharples et al., 2013a). The lateral fire spread appears to be driven by fire whirls formed over the leeward slope, and has qualitative similarities to a dynamic fire spread process described briefly by Countryman (1971).

WRF-Fire is one of a number of coupled atmospherefire models capable of directly modelling two-way coupled atmosphere-fire interactions. Other examples include the CAWFE (Clark et al., 1996a, b), HIGRAD/FIRETEC (Linn et al., 2002, 2007; Cunningham and Linn, 2007) and MésoNH-ForeFire (Filippi et al., 2009, 2011) coupled models. Simpson et al. (2013) used WRF-Fire to model the development of a wildland fire ignited on the leeward slope of a triangular-shaped ridge oriented perpendicularly to the background winds. They concluded that the resulting lateral fire spread, which qualitatively matched that observed during the 2003 Canberra bushfires (Sharples et al., 2012), is driven by fire whirls that formed due to an interaction between the terrain-modified winds and pyro-convectively driven vertical circulations above the fire. This explanation permits the phenomenon to be characterised as "vorticity-driven lateral spread (VLS)". Sharples et al. (2013a) subsequently used WRF-Fire to examine the effect of varying the background wind speed on the occurrence and characteristics of VLS, and found a lower threshold in the background wind speed for VLS. The existence of environmental thresholds for VLS has important implications for the management of wildland fires in rugged terrain, although these environmental thresholds are not presently well understood.

This study aims to examine the effect of varying the horizontal and vertical grid spacing, and enabling and disabling the fire-to-atmosphere coupling, in the WRF-Fire model of the occurrence and characteristics of VLS. It is expected that there will be a threshold in the horizontal and vertical grid spacing, above which VLS is no longer modelled. This will indicate the spatial scale at which the dynamic interaction driving the lateral fire spread operates. The WRF-Fire model and the configuration used in this study are discussed below, followed by the simulation results and a number of conclusions.

\section{Numerical modelling}

\subsection{WRF-Fire}

The WRF-Fire coupled atmosphere-fire model is included as part of the Weather Research and Forecasting (WRF) numerical weather prediction model. Version 3.5 of the Advanced Research WRF (Skamarock et al., 2008) is used in this study, and includes a version of WRF-Fire similar to that described by Mandel et al. (2011). Coen et al. (2013) and Mandel et al. (2014) have recently described other versions of the WRFFire and the WRF and SFIRE coupled atmosphere-fire models. The WRF-Fire model has developed out of the CAWFE coupled atmosphere-fire model used by Clark et al. (1996a, b, 2004) and Coen (2005). Kochanski et al. (2013a, b, c, d) have recently presented several validation case studies for the WRF and SFIRE coupled model, and Peace and Mills (2012) used the model to study the 2007 Kangaroo Island bushfires in Australia. Simpson et al. (2013) and Sharples et al. (2013a) have previously used the WRF-Fire model to investigate VLS, and a similar model configuration is adopted in this study.

The WRF model utilises fully compressible nonhydrostatic equations and a mass-based terrain-following coordinate system. In this study, WRF is used in a large eddy simulation configuration, referred to as WRF-LES (large eddy simulation) (Moeng et al., 2007; Mirocha et al., 2010; Kirkil et al., 2012). WRF-LES explicitly resolves the gridscale atmospheric eddies, whereas the subgrid-scale motions are modelled using a subfilter-scale stress model. WRF-LES is therefore well suited to modelling turbulent atmospheric flows, such as those associated with VLS. In this paper, the 2-D wildland fire spread model to which WRF-LES is coupled will be referred to as SFIRE. Each wildland fire ignited in SFIRE is modelled as a temporally evolving perimeter that advances through the model domain using a level set function. The SFIRE model grid is defined on a subgrid of the WRF-LES horizontal model grid, and the horizontal extents of the SFIRE and WRF-LES model domains coincide. The terrain in SFIRE is defined at a higher spatial resolution than in WRF-LES when the subgrid ratio is greater than 1, but is otherwise identical. A total of 13 different fuel types, based on the 13 Anderson fuel categories (Anderson, 1982), are available by default in SFIRE. The parameterised fuel properties include the initial mass loading, fuel depth, surfacearea-to-volume ratio, moisture content of extinction and rate of mass loss following ignition.

The rate of spread is calculated each time step at each point along the fire perimeter using Rothermel's semi-empirical fire spread model (Rothermel, 1972):

$R=R_{0}\left(1+\phi_{\mathrm{W}}+\phi_{\mathrm{S}}\right)$, 
where $R$ is the rate of spread, $R_{0}$ is the base rate of spread in the absence of wind or slope, and $\phi_{\mathrm{W}}$ and $\phi_{\mathrm{S}}$ are wind and slope correction factors. Unless otherwise stated, the rate of spread values presented in this study are calculated from a mean average over 5 min intervals. $R_{0}$ is determined solely by the parameterised fuel properties, whereas $\phi_{\mathrm{S}}$ and $\phi_{\mathrm{S}}$ are calculated using the local terrain slope and mid-flame height winds. In this version of SFIRE, $\phi_{\mathrm{S}}$ has a minimum value of zero. In this version of WRF-Fire, the mid-flame height winds are calculated through the vertical interpolation of WRF-LES winds, using the logarithmic wind profile, to an estimated mid-flame height. As noted by Coen et al. (2013), the height and location relative to the fire front at which to take the winds remains an active research area.

The coupling from the fire to the atmosphere is achieved in WRF-Fire through the conversion of fuel mass to latent and sensible heat in SFIRE. The sensible and latent heat is injected each time step into WRF-LES and subsequently affects the local atmospheric conditions, including the midflame height winds. For each kilogram of fuel combusted in SFIRE, 17.43 MJ of sensible heat is produced, and the sensible heat flux is inserted as an additional source term to the equation for the potential temperature in WRF-LES. In this study, the corresponding latent heat flux, which is inserted as a source term for the water vapour concentration, is around a factor of 10 smaller than the sensible heat flux. The sensible and latent heat fluxes are individually aggregated across the SFIRE model subgrid and used to calculate the heat fluxes for each WRF-LES model grid vertical column. The vertical distribution of the heat fluxes within each WRF-LES model grid column is controlled by an exponential decay function, with the greatest quantity of sensible and latent heat injected into the lowest model vertical levels. The fire-to-atmosphere feedback in WRF-Fire can be switched off by applying a multiplier of zero to the heat fluxes calculated by SFIRE.

\subsection{Model configuration}

The WRF-Fire model is used to conduct 16 simulations, which are divided into two groups of 8 simulations with the fire-to-atmosphere coupling enabled and then disabled. Within each group, the WRF-LES horizontal and vertical grid spacing is set to $25,30,40,50,60,70,80$ and $90 \mathrm{~m}$. The subgrid ratio used between the SFIRE and WRF-LES model grids is set to eight in each simulation, resulting in a minimum and maximum horizontal grid spacing of 3.125 and $11.25 \mathrm{~m}$ in SFIRE. This range of grid spacings was chosen as it sufficiently demonstrates the effect of spatial resolution on modelling VLS with WRF-Fire. Individual simulations are named according to whether the fire-to-atmosphere coupling is enabled ("C") or disabled ("N"), followed by the horizontal grid spacing in metres. For example, $\mathrm{C} 30$ is a coupled simulation with a horizontal grid spacing of $30 \mathrm{~m}$ in WRF-LES.

In this study, WRF-Fire is used in a highly idealised configuration. The microphysics, longwave and shortwave radiation, urban surface physics, planetary boundary layer and cumulus parameterisations are disabled. An idealised domain is used with a prescribed wind profile, rather than real terrain and weather data. Diffusion in physical space is calculated using the velocity stress tensor and eddy viscosities are calculated using a 3-D prognostic 1.5-order turbulence closure scheme. A Rayleigh damping scheme (Klemp et al., 2008) is used in the top $1 \mathrm{~km}$ of the model to absorb upward propagating gravity wave energy and to dampen the pyro-convection. The lateral and top boundary conditions are open radiative, whereas the lower boundary is free slip. The main model time integration in WRF-Fire is performed using a third-order Runge-Kutta scheme and the primary time step chosen is $0.0625 \mathrm{~s}$ for each simulation, regardless of spatial resolution. The secondary time step is a time-split small step for acoustic and gravity wave modes, and is set to one eighth of the primary time step. The initial $20 \mathrm{~min}$ of each simulation are considered the spin-up period and are not included in the time-averaging calculations. Only limited atmospheric turbulence is spun up in WRF-Fire during the initialisation period, due to the absence of any sources of surface friction or surface heating. The total simulation time, including the spin-up period, is $2 \mathrm{~h}$.

The horizontal extent of the WRF-Fire model domain is approximately $8 \times 8 \mathrm{~km}$, and the number of WRF-LES and SFIRE model grid cells varies with the horizontal and vertical grid spacing. A triangular-shaped ridge is located within both the WRF-LES and SFIRE model domains. The ridge's windward slope begins $2 \mathrm{~km}$ to the east of the western lateral boundary, and the windward and leeward slopes are 20 and $35^{\circ}$, respectively. In contrast to the studies by Simpson et al. (2013) and Sharples et al. (2013a), the ridge's peak height of around $600 \mathrm{~m}$ is smaller, and the ridge height decreases linearly at its southern and northern edges at $30^{\circ}$. A $400 \mathrm{~m}$ wide region of flat terrain is located at the southern and northern lateral boundaries to allow the background winds to flow around the ridge. A cubic spline interpolation is used to partially smooth the terrain edges.

The WRF-Fire model top is initially set to $5 \mathrm{~km}$ and the vertical non-stretched grid spacing is initially equal to the horizontal grid spacing in WRF-LES. There are minor variations in the vertical grid spacing with time due to the use of sigma vertical levels, and the model top varies by up to $200 \mathrm{~m}$ in each simulation. Each simulation is initialised with horizontally homogeneous vertical profiles of the water vapour mixing ratio, the potential temperature, and the horizontal winds. The water vapour mixing ratio is initially set to zero at all heights. The potential temperature is initially set to $300 \mathrm{~K}$ between the surface and $4 \mathrm{~km}$, and then increased linearly to $310 \mathrm{~K}$ between 4 and $5 \mathrm{~km}$. This stable layer acts to prevent considerable descent of the model top towards the surface. A temporally uniform westerly wind is prescribed at the western lateral boundary. The vertical wind profile at this boundary is given by $U(z)\left(\mathrm{m} \mathrm{s}^{-1}\right)$ : 
$U(z)=U_{0} P(z) \hat{\boldsymbol{x}}$,

where $U_{0}$ denotes the background wind speed $\left(\mathrm{m} \mathrm{s}^{-1}\right), P(z)$ prescribes the vertical wind profile and $\hat{\boldsymbol{x}}$ denotes the unit vector along the $x$ axis, towards the east. $P(z)$ is defined as

$P(z)= \begin{cases}\left(\frac{z}{200}\right)^{\frac{1}{7}}, & z \leq 200 \\ 1, & z>200,\end{cases}$

where $z$ is the height $(\mathrm{m})$. In contrast to the studies by Simpson et al. (2013) and Sharples et al. (2013a), the wind profile power law has an exponent of $1 / 7$. This exponent is a standard alternative to the logarithmic wind profile when the atmospheric stability is neutral (Justus et al., 1976). In this study, the background wind speed is set to $15 \mathrm{~m} \mathrm{~s}^{-1}$ for each simulation.

Fuel type 13, which corresponds to the heavy logging slash Anderson fuel category (Anderson, 1982), is assigned homogeneously across the SFIRE model grid. Figure 1 shows the variation in time of the total heat flux for an SFIRE model grid cell following its ignition. The exponential decrease in the total heat flux is associated with a weighting parameter defined individually for each fuel type, and in this case results in a halving of the heat flux approximately every $15 \mathrm{~min}$. This fuel type has a base rate of spread of around $0.12 \mathrm{~km} \mathrm{~h}^{-1}$. In order to estimate the mid-flame height wind speed, the WRF-LES winds are horizontally and vertically interpolated to a height of $1 \mathrm{~m}$ a.g.l. (above ground level). The vertical interpolation uses the logarithmic wind profile with a surface roughness length of $0.1 \mathrm{~m}$. The choice of height and the surface roughness in the vertical interpolation represent default values in WRF-Fire, and are not related to physical properties of heavy logging slash fuels. As the fuel type and slope are identical for each WRF-Fire simulation, any difference in the fire spread is due solely to variations in the mid-flame height wind conditions, and the subsequent dynamic twoway atmosphere-fire coupling, if the fire-to-atmosphere coupling is enabled.

The fire is ignited at the end of the 20 min spin-up period. The fire perimeter is ignited out to a distance of $40 \mathrm{~m}$ in all directions away from a south-north line of $200 \mathrm{~m}$ in length. This south-north line is centred on the $y$ axis and is located towards the base of the leeward slope, which emulates the laboratory experiments described by Sharples et al. (2010) and Farinha (2011). The fire is ignited at two locations simultaneously, starting from the northern and southern edges of the south-north ignition line and spreading towards the centre of the south-north line. Following this ignition process, the fire is allowed to spread freely throughout the model domain for the remainder of the simulation. The prescribed ignition is not included in any rate of spread calculations presented below. In a real situation, a spot fire could be ignited in this location due to the transportation of firebrands downwind from a wildland fire located upwind of the leeward slope.

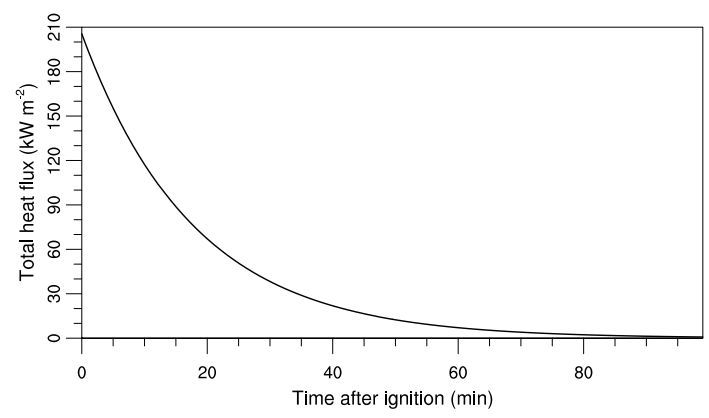

Figure 1. Variation in time of the combined sensible and latent (i.e. total) heat flux for an SFIRE model grid cell immediately following its ignition in WRF-Fire.

\section{Results}

\subsection{Fire spread stages}

The wildland fire spread can be visualised using the ignition time for each SFIRE model grid cell and is shown for each WRF-Fire simulation in Fig. 2. Three distinct stages of fire spread can be identified from these simulations, not including the prescribed ignition described previously:

1. Upslope: the fire front advances upslope from the ignition region to the ridge line.

2. Initial lateral: the fire spreads laterally across the leeward slope at a rate higher than the base rate of spread. This can occur during the upslope fire spread.

3. Intermittent lateral: the lateral extensions of the fire perimeter continue to spread intermittently, at a rate that is highest on the leeward slope and close to the ridge line.

In those coupled simulations with a horizontal grid spacing of 25 to $80 \mathrm{~m}$, there is considerable lateral fire spread along the leeward slope, particularly near the ridge line. In contrast, there is no appreciable lateral fire spread subsequent to the prescribed ignition in the $\mathrm{C} 90$ and non-coupled simulations. This indicates that resolving the fire whirls is critical for modelling VLS with WRF-Fire.

\subsection{Upslope fire spread in non-coupled simulations}

In each non-coupled simulation, the fire front develops a parabolic shape as it advances upslope after the prescribed ignition. The parabolic shape develops as a consequence of the ignited fire shape, with a rounded fire perimeter on its southern and northern edges, and the method used in WRF-Fire to account for the effect of slope on the rate of spread (Mandel et al., 2011). During the 25 to $30 \mathrm{~min}$ period following the prescribed ignition in which the fire advances upslope, the westerly rate of spread typically varies between 1.0 and $1.2 \mathrm{~km} \mathrm{~h}^{-1}$ for each simulation, as shown 

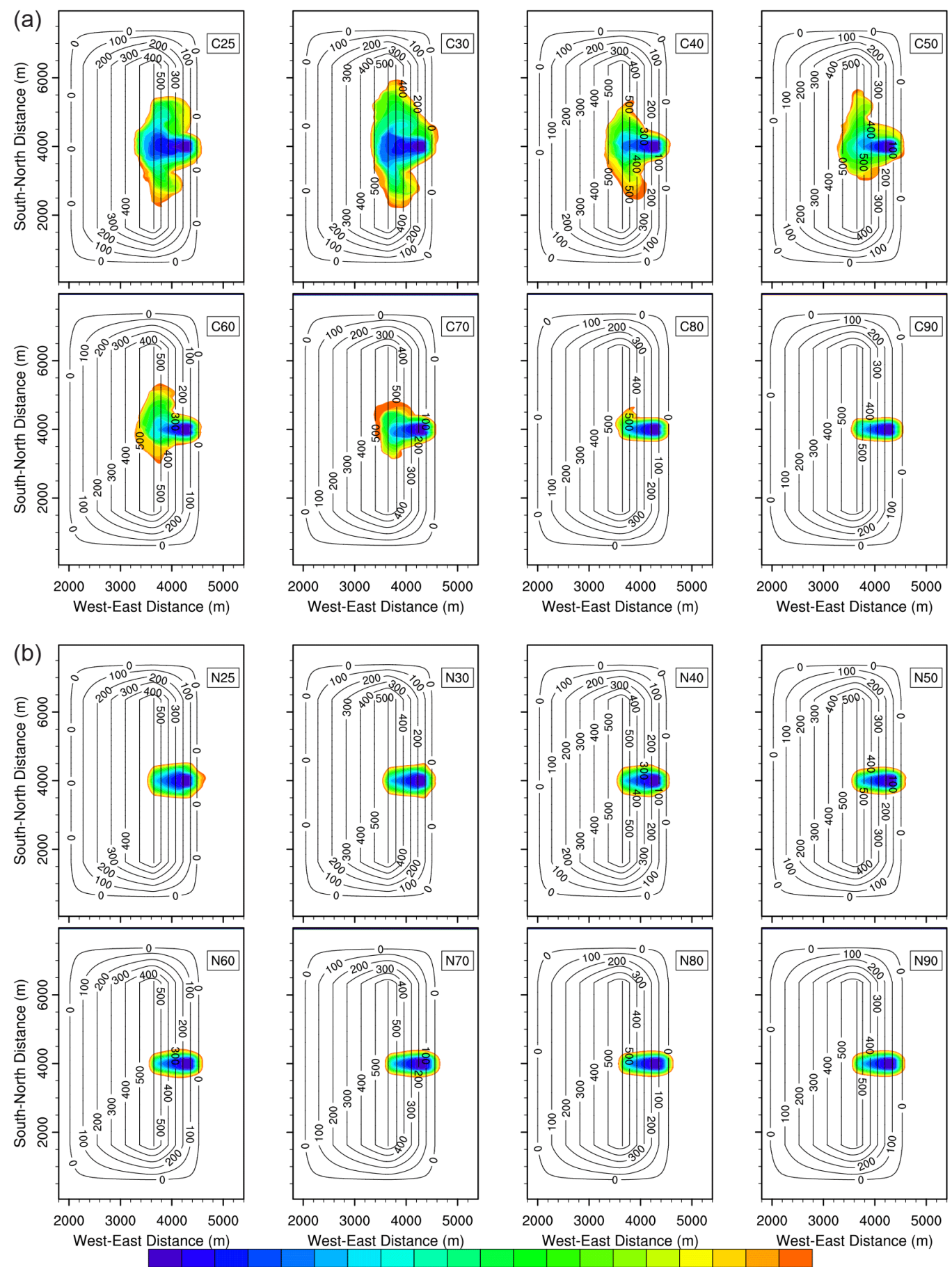

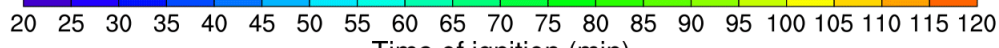

Figure 2. Time of ignition ( $\mathrm{min}$ ) for each SFIRE model grid cell, and terrain height (m) line contours for each (a) coupled and (b) non-coupled simulation. Simulation names are provided in the top-right corner of each individual plot.

in Fig. 3a. This is approximately 10 to 12 times higher than the base rate of spread. The limited variability in the westerly rate of spread between simulations indicates that the resolution of the terrain-modified mid-flame height winds does not appreciably affect the upslope rate of spread for this particular model configuration.

Once the fire front encounters the ridge line and the slope is no longer positive, the westerly rate of spread decreases towards the base rate of spread. The fire then continues to 
Table 1. Time after ignition (min) and lowest height $(\mathrm{m})$ on a leeward slope at which the initial lateral spread occurs for each coupled simulation. Also included is the time after ignition $(\mathrm{min})$ at which the fire perimeter first reaches the ridge line.

\begin{tabular}{lcccccc}
\hline Simulation & \multicolumn{2}{c}{ Northerly lateral spread } & & \multicolumn{2}{c}{ Southerly lateral spread } & Ridge \\
\cline { 2 - 3 } & $\begin{array}{c}\text { Height } \\
(\mathrm{m})\end{array}$ & $\begin{array}{c}\text { Time } \\
(\mathrm{min})\end{array}$ & & $\begin{array}{c}\text { Height } \\
(\mathrm{m})\end{array}$ & $\begin{array}{c}\text { Time } \\
(\mathrm{min})\end{array}$ & \\
$(\mathrm{min})$
\end{tabular}

spread in all directions at approximately the base rate of spread for the remainder of the simulation, resulting in a slowly expanding fire perimeter, as seen in Fig. 2b. Figure 4 shows the time-averaged mid-flame height horizontal winds for the N25 simulation. The terrain-modified winds are fairly consistent in time after the WRF-Fire initialisation period, and are weak across the leeward slope. The upslope rate of spread is instead dominated by the slope correction term in Eq. (1).

\subsection{Upslope and initial lateral fire spread in coupled simulations}

The westerly rate of spread is typically much more variable, both in time and between simulations, for the coupled simulations than for the non-coupled simulations, as demonstrated by directly comparing Fig. $3 \mathrm{a}$ and $\mathrm{b}$. The peak westerly rates of spread are $2.90,3.14,2.28,1.50$ and $1.79 \mathrm{~km} \mathrm{~h}^{-1}$ in the $\mathrm{C} 25, \mathrm{C} 30, \mathrm{C} 40, \mathrm{C} 50$ and $\mathrm{C} 70$ simulations, compared with $1.16,1.18,1.20,1.20$ and $1.15 \mathrm{~km} \mathrm{~h}^{-1}$ in the $\mathrm{N} 25, \mathrm{~N} 30$, N40, N50 and N70 simulations. This demonstrates that inclusion of the fire-to-atmosphere coupling in WRF-Fire can markedly affect the upslope rate of spread and initial fire front development, particularly at a higher spatial resolution. For the $\mathrm{C} 60, \mathrm{C} 80$ and $\mathrm{C} 90$ simulations, the peak upslope rate of spread is almost identical to the equivalent non-coupled simulations, indicating limited impact of the fire-modified atmospheric dynamics on the upslope rate of spread.

In the coupled simulations, the fire front also initially develops a parabolic shape as it advances upslope from the prescribed ignition, similarly to in the non-coupled simulations. However, the turbulent fire-modified mid-flame height winds can result in asymmetric fire front advancement, which represents the start of the initial lateral fire spread stage, prior to the fire front reaching the ridge line. The approximate time after ignition and height on the leeward slope of this initial lateral spread is provided in Table 1 for each coupled simulation, alongside the time at which the fire front first encounters the ridge line. The initial lateral fire spread typically
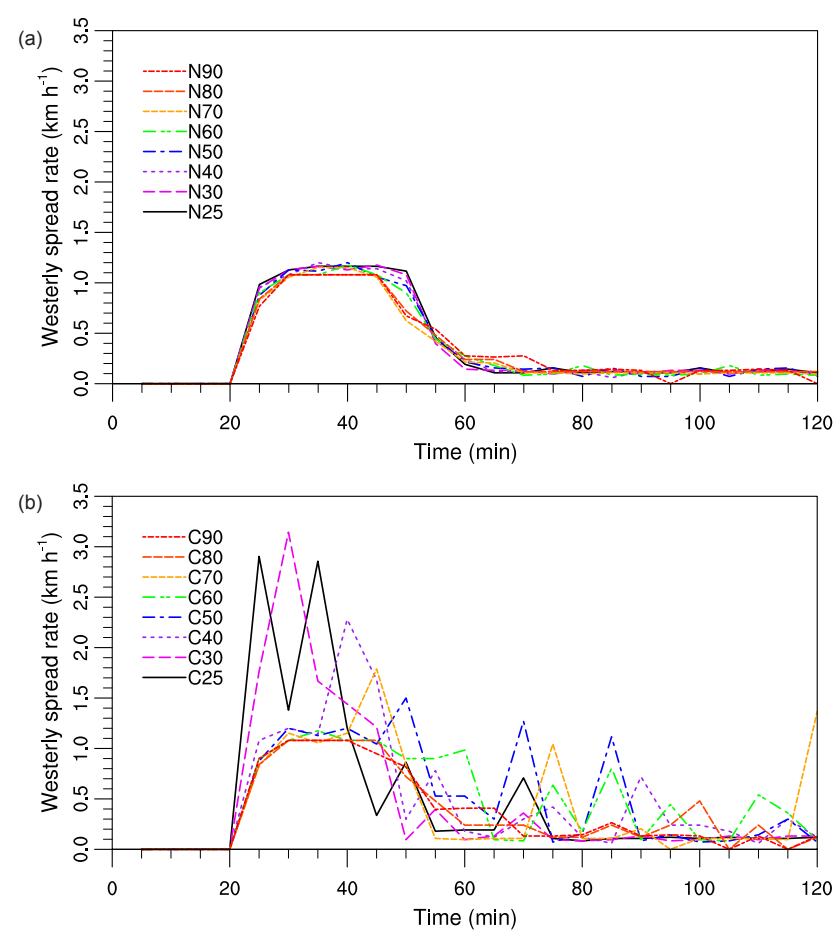

Figure 3. Westerly rate of spread $\left(\mathrm{km} \mathrm{h}^{-1}\right)$ following the prescribed ignition for each (a) non-coupled and (b) coupled simulation.

begins earlier and lower on the leeward slope as the horizontal and vertical grid spacing decreases. This initial lateral spread prior to the arrival of the fire front at the ridge line was not discussed by Simpson et al. (2013) and Sharples et al. (2013a).

In the $\mathrm{C} 25$ and $\mathrm{C} 30$ simulations, fire whirls with nonzero vertical and horizontal vorticity vector components are formed non-symmetrically in close proximity to the fire perimeter during the upslope fire spread stage, as shown for the $\mathrm{C} 25$ simulation in Fig. 5. The fire whirls drive the initial lateral fire spread, to beyond the initial south-north extent 

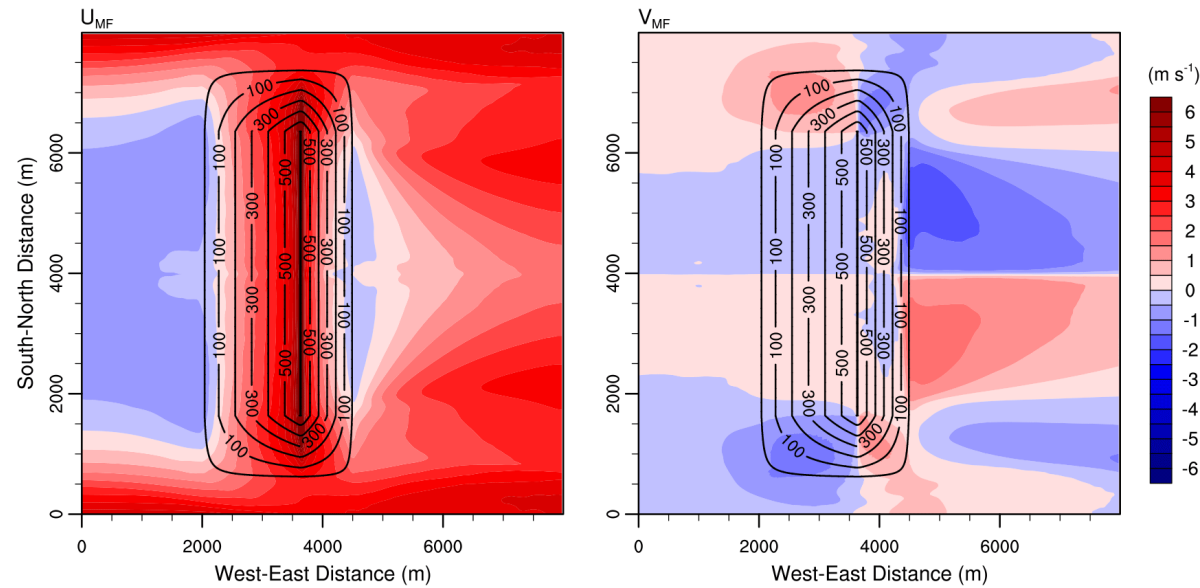

Figure 4. Average mid-flame height (a) $U$ and (b) $V$ component wind speeds ( $\mathrm{m} \mathrm{s}^{-1}$ ), based on time averaging from 20 to $120 \mathrm{~min}$, for the N25 simulation.
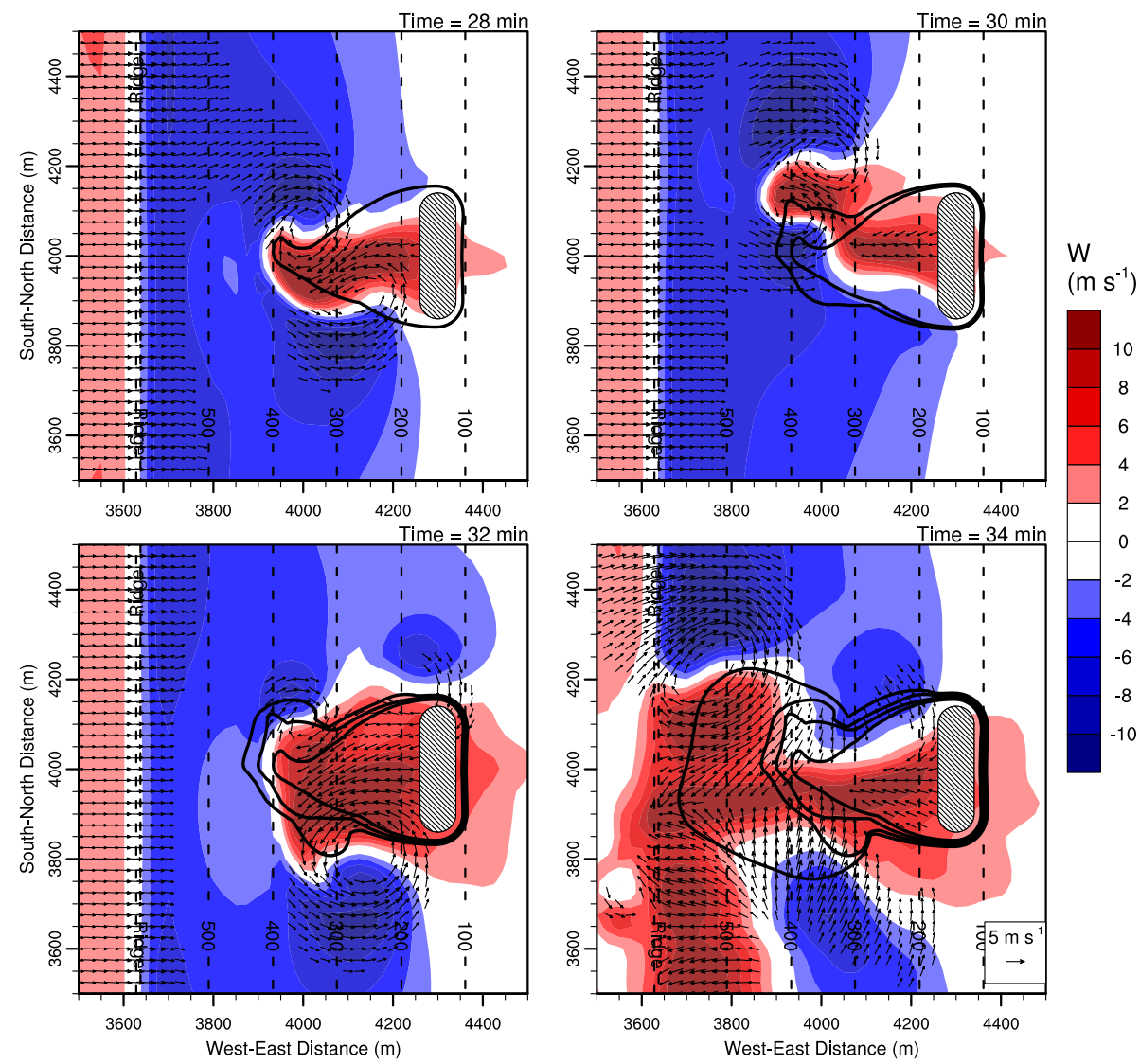

Figure 5. Vertical velocity, $W\left(\mathrm{~m} \mathrm{~s}^{-1}\right)$, at approximately $40 \mathrm{~m}$ a.g.l., and horizontal mid-flame height wind vectors, where the wind speed is at least $5 \mathrm{~m} \mathrm{~s}^{-1}$, at a time of (a) 28, (b) 30, (c) 32 and (d) $34 \mathrm{~min}$ for the C25 simulation. The expanding fire perimeter every 2 min is shown by the thick black lines, whereas the dashed lines indicate the terrain height at $100 \mathrm{~m}$ intervals. A reference westerly wind vector of $5 \mathrm{~m} \mathrm{~s}{ }^{-1}$ is shown in the bottom right of (d), and the dashed pattern filled region indicates the prescribed ignition region. 

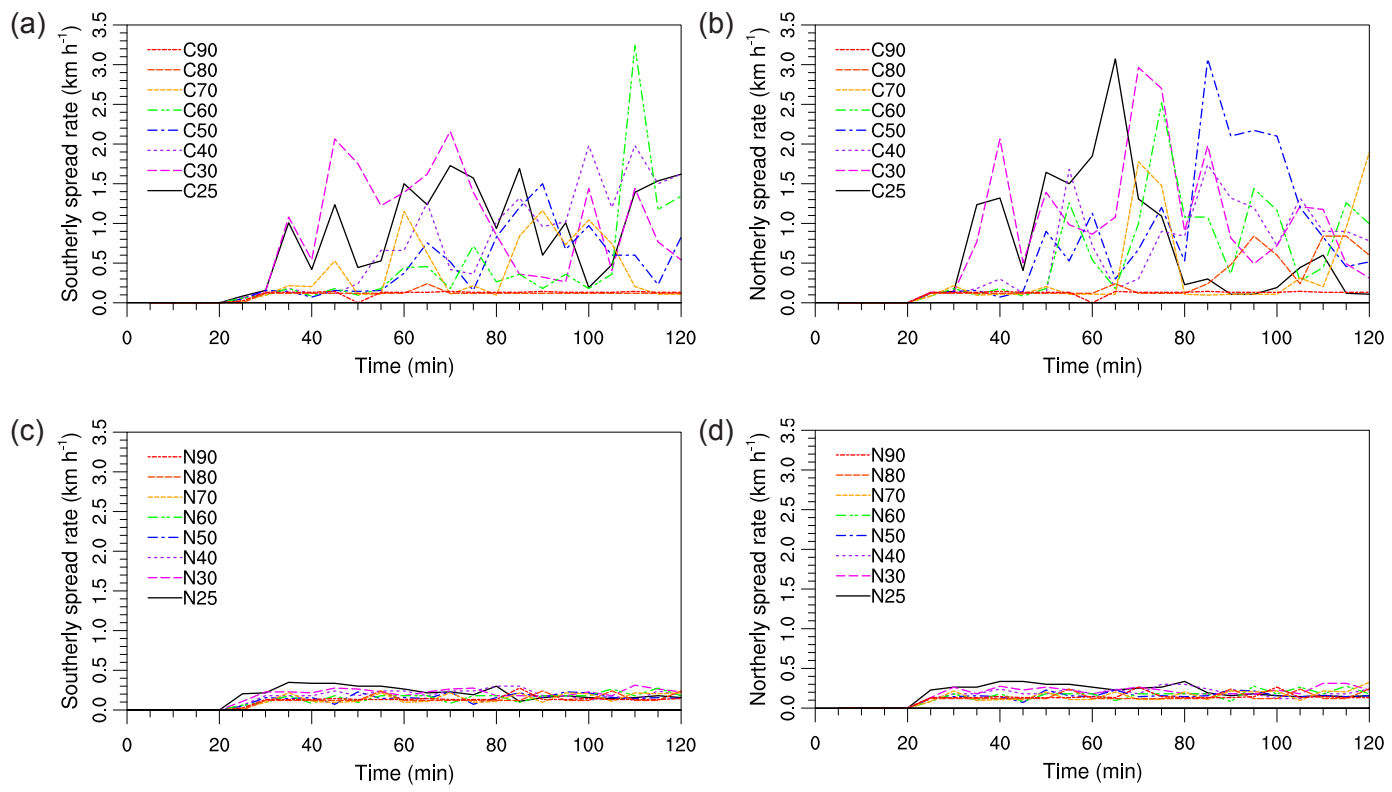

Figure 6. Southerly $(\mathbf{a}, \mathbf{c})$ and northerly $(\mathbf{b}, \mathbf{d})$ rates of spread $\left(\mathrm{km} \mathrm{h}^{-1}\right)$ following the prescribed ignition for each (a, b) coupled and (c, d) non-coupled simulation.

prescribed in the ignition, during the upslope fire spread in both the $\mathrm{C} 25$ and $\mathrm{C} 30$ simulations. It also contributes towards the high peak westerly rates of spread of 2.90 and $3.14 \mathrm{~km} \mathrm{~h}^{-1}$, respectively. Fire whirls are also present during the upslope fire spread stage in the other coupled simulations, but do not affect the upslope or lateral rate of spread to the same extent as in the C25 and C30 simulations. Vortices with a vertical component are entirely absent in the non-coupled simulations, demonstrating that the vortices are fire whirls formed due to an interaction between the fire, the terrain and the atmosphere.

In the $\mathrm{C} 25, \mathrm{C} 30, \mathrm{C} 40, \mathrm{C} 50, \mathrm{C} 60$ and $\mathrm{C} 70$ simulations, the fire advances several hundred metres beyond the ridge line and across the windward slope. In contrast, fire spread onto the windward slope was not observed during the VLS events in the 2003 Canberra bushfires (Sharples et al., 2012). The advancement of the modelled fire onto the windward slope can be partly attributed to the fire-induced easterly winds, which develop as an inflow towards the base of the pyroconvective updraft above the fire front. These easterly winds can dominate over the background westerly winds across the leeward and upper windward slopes, and therefore facilitate fire spread across the upper windward slope. In addition, there is currently no reduction in the rate of spread due to negative slopes in WRF-Fire, which contradicts empirical data (Weise and Biging, 1997).

\subsection{Intermittent lateral fire spread in coupled simulations}

For those coupled simulations in which VLS occurs, the lateral extensions of the fire front close to the ridge line become the most rapidly advancing parts of the fire perimeter once the upslope and initial lateral fire spread stages have concluded. The southerly and northerly fire fronts continue to advance laterally across the leeward slope in intermittent jumps for the remainder of the simulation, as demonstrated by Fig. $6 \mathrm{a}$ and $\mathrm{b}$. The peak lateral rates of spread in the $\mathrm{C} 25$, $\mathrm{C} 30, \mathrm{C} 40, \mathrm{C} 50, \mathrm{C} 60, \mathrm{C} 70, \mathrm{C} 80$ and $\mathrm{C} 90$ simulations are factors of 8.8, 9.6, 6.6, 13.3, 11.6, 5.9, 3.5 and 1.9 times higher than in the equivalent non-coupled simulations. This erratic number sequence arises due to the complex variation in the effect of the two-way atmosphere-fire coupling on the lateral spread. The fire-to-atmosphere coupling is therefore shown to increase the lateral rate of spread, as further demonstrated by comparing the coupled and non-coupled lateral rates of spread, shown in Fig. 6.

The lateral fire spread occurs asymmetrically for each VLS simulation, resulting in differences between the peak southerly and northerly rates of spread. Most commonly, the peak lateral rate of spread is highest towards the north $(\mathrm{C} 25$, $\mathrm{C} 30, \mathrm{C} 50, \mathrm{C} 70$ and C80), rather than towards the south (C40 and C60), as shown in Fig. 6. Given the identical and symmetric terrain and prescribed ignition used in each coupled simulation, the asymmetry in the lateral fire spread must originate from numerical instability in the WRF-Fire model, caused by round-off error. The resulting asymmetries then grow in magnitude due to the effects of atmosphere-fire 

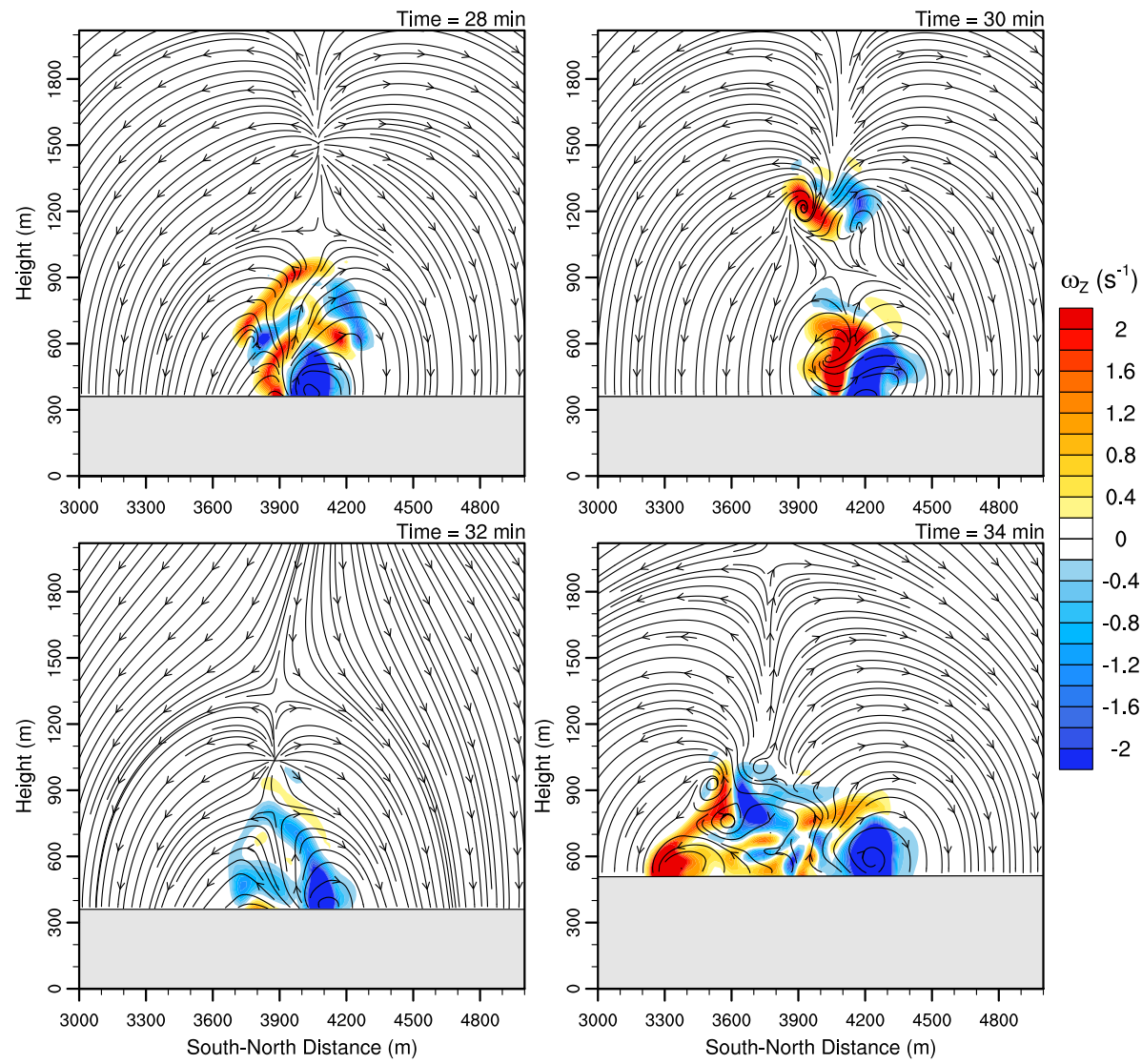

Figure 7. Magnitude of the vorticity along the $\hat{z}$ unit vector direction, $\omega_{Z}\left(\mathrm{~s}^{-1}\right)$, and streamlines derived from the $V$ and $W$ component winds along a vertical cross-section parallel to the ridge line, and through the leeward slope, at a time of (a) 28, (b) 30 , (c) 32 and (d) 34 min for the C25 simulation. The cross-sections are taken at a west-east distance of (a, b, c) 4000 and (d) $3800 \mathrm{~m}$, and the grey-filled region indicates the height of the leeward slope along the cross-section.

coupling, and so are therefore associated with both the numerical instability within the WRF-Fire model, and the dynamical instability in VLS. Similar asymmetric fire spread has been noted in the CAWFE model by Clark et al. (2004).

The occurrence and irregularity of the lateral fire spread across the leeward slope is attributable to the movement of fire whirls across the flanks of the fire perimeter. The 3-D vorticity vector field is calculated in WRF-LES as the curl of the 3-D wind field. The characteristics of the fire whirls driving the initial lateral fire spread can be inferred for the $\mathrm{C} 25$ simulation from Figs. 5 and 7. They show that the fire whirl located over the northern flank of the fire is associated with clockwise rotation about both the $x$ and $z$ axes. Although not shown, the fire whirl located over the southern flank is associated with anticlockwise rotation about the $x$ and $z$ axes. The circulating flow at the mid-flame height driving the lateral fire spread is centred on the pyro-convectively driven vertical circulation, seen as adjacent updrafts and downdrafts close to the flanks of the fire perimeter in Fig. 5. The vertical circulations vary in size, location and intensity throughout the simulation as the fire front develops, but are frequently located close to the lateral flanks of the fire front, such as at 28 and 32 min in the $\mathrm{C} 25$ simulation.

The horizontal and vertical grid spacing used in the WRFFire model affects the resolution of the fire whirls, and therefore also the two-way atmosphere-fire coupling and resulting lateral rate of spread. For example, the average lateral rates of spread after ignition are 0.88 and $1.04 \mathrm{~km} \mathrm{~h}^{-1}$ in the $\mathrm{C} 25$ and C30 simulations, compared with lower values of $0.78,0.71$, $0.61,0.42,0.22$ and $0.13 \mathrm{~km} \mathrm{~h}^{-1}$ in the $\mathrm{C} 40, \mathrm{C} 50, \mathrm{C} 60, \mathrm{C} 70$, $\mathrm{C} 80$ and C90 simulations. It is possible that using even finer grid spacing in WRF-Fire could further increase the average and peak lateral rate of spread. However, the similarity in the peak and average lateral spread rates between the C25 and C30 simulations suggests that a near-optimal resolution has been reached. In addition, it is difficult to complete a WRFFire simulation at higher resolution for an otherwise identical model configuration, due to the intense updrafts in the pyroconvective plume. 


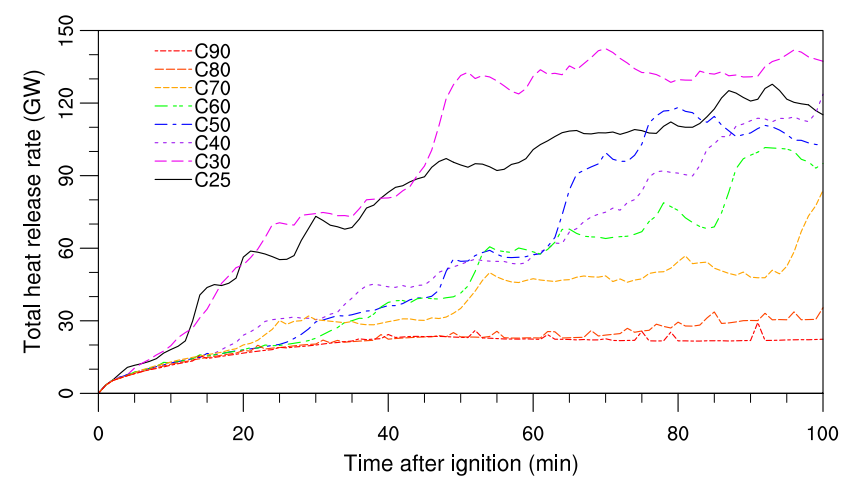

Figure 8. Variation in time of the domain-aggregated combined sensible and latent (i.e. total) heat release rate $(\mathrm{GW})$ for each coupled simulation.

\subsection{Power and pyro-convection}

The domain-aggregated total heat release rate, subsequently referred to as the "power of the fire", is shown for each coupled simulation in Fig. 8. The power of the fire is highest for the C30 simulation and lowest for the C90 simulation. In general, the peak and average power values of the fire increase as the horizontal and vertical grid spacing decrease, from 90 to $30 \mathrm{~m}$. This increase in the power of the fire occurs due to an increase in the fire area, and is therefore associated with the dynamic lateral fire spread. An increase in either the upslope or lateral rate of spread, relative to the equivalent non-coupled simulation, therefore results in an increase in the power of the fire. The power of the fire can decrease when there is insufficient ignition of fuel to replace the mass loss, due to the parameterised combustion in SFIRE of fuel that has previously been ignited.

For those simulations in which VLS occurs, the laterally advancing fire fronts become the dominant contributor to the power of the fire once the upslope fire spread stage has concluded. This supports the observation that VLS is accompanied by intense pyro-convection (Sharples et al., 2012) due to the rapid ignition of fuel on the leeward slope. The resolved mean kinetic energy of the turbulent portion of the atmospheric flow, hereafter referred to as the turbulent kinetic energy (TKE), is calculated for each WRF-LES model grid cell from the time of ignition to the end of the simulation, and is shown for the C25 simulation in Fig. 9a. In the coupled simulations, the heat release rate during the upslope and lateral fire spread is sufficient for the near-fire and downwind atmospheric dynamics to be dominated by pyro-convection. For example, the peak TKE values for the C25 and N25 simulations are 196.0 and $6.6 \mathrm{~m}^{2} \mathrm{~s}^{-2}$. In the $\mathrm{C} 25$ simulation, the TKE is high, indicating highly variable winds, over the leeward slope and in the pyro-convective plume extending downwind from the ridge.

Simpson et al. (2013) and Sharples et al. (2013a) have previously demonstrated that the background winds can tilt the
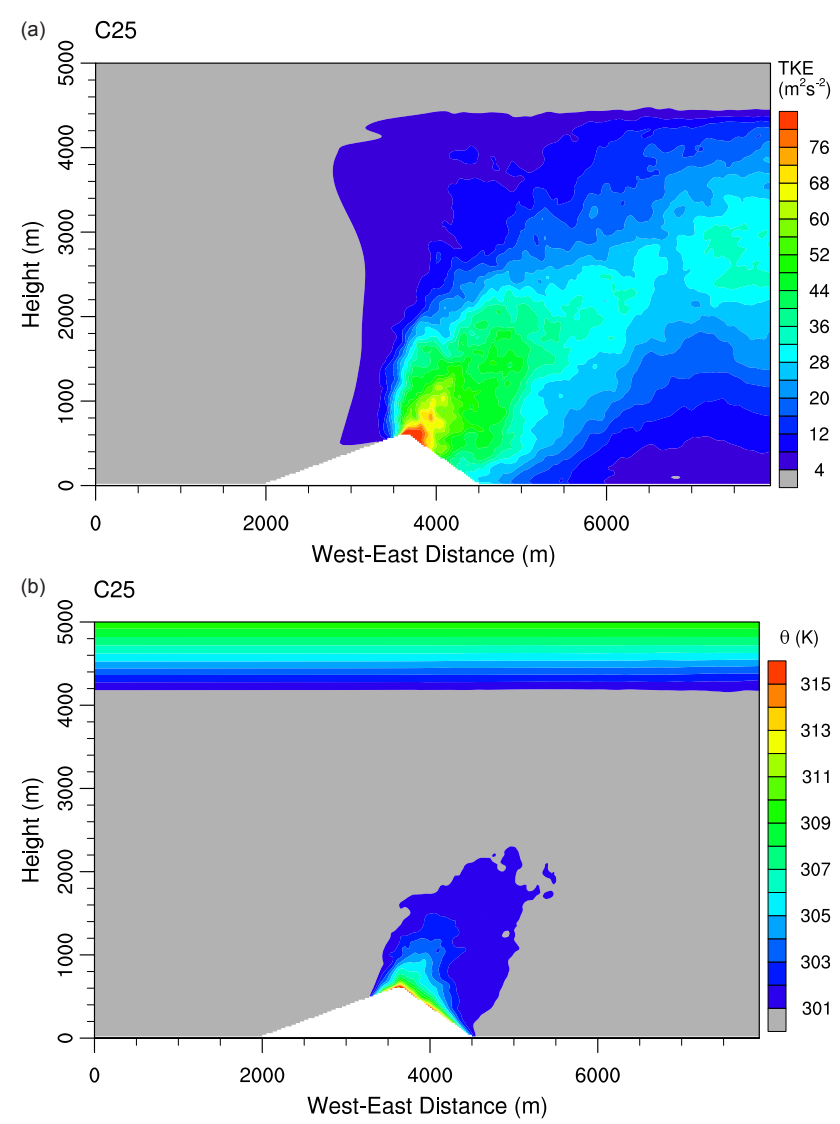

Figure 9. (a) Resolved turbulent kinetic energy, TKE $\left(\mathrm{m}^{2} \mathrm{~s}^{-2}\right)$, and (b) potential temperature, $\theta(\mathrm{K})$, averaged from 20 to $120 \mathrm{~min}$, along a vertical cross-section through the centre of the WRF-Fire model domain for the $\mathrm{C} 25$ simulation.

pyro-convective plume relative to the ground. The combination of a tilted and intense pyro-convective plume and highly turbulent near-fire and downwind atmospheric dynamics provides favourable conditions for spotting. This result generally supports the hypothesis, presented by Sharples et al. (2012), that extensive downwind spotting played a critical role in the downwind extension of the active flaming region seen in VLS events during the 2003 Canberra bushfires. However, WRF-Fire does not currently include a midto long-range spotting model, so therefore cannot be used to test this theory explicitly.

The heat released from the fire also directly affects the near-fire and downwind atmospheric potential temperature, which is shown for the $\mathrm{C} 25$ simulation in Fig. 9b. The time-averaged potential temperature peaks at $319 \mathrm{~K}$, directly above the ridge line, compared with the background temperature of $300 \mathrm{~K}$ up to a height of $4 \mathrm{~km}$. Although potential temperature anomalies greater than $1 \mathrm{~K}$ extend downwind from the leeward slope, they are not in contact with the flat terrain. The pyro-convective plume in the coupled simulations would not contribute towards fuel pre-drying downwind of 
the leeward slope, as the air is sufficiently buoyant to rise away from the surface. The potential temperature anomalies are more spatially confined than the fire-induced atmospheric turbulence, and are therefore not a good proxy measure of the spatial extent of the pyro-convective plume.

\section{Conclusions}

The WRF-Fire simulations presented in this study demonstrate that both high spatial resolution and two-way atmosphere-fire coupling are required for WRF-Fire to model VLS on a steep leeward slope, which is consistent with the results presented by Simpson et al. (2013) and Sharples et al. (2013a). VLS did not occur in the non-coupled simulations, regardless of spatial resolution, whereas VLS occurred in most of the coupled simulations, aside from in the C90 simulation. This suggests that a horizontal and vertical grid spacing of $80 \mathrm{~m}$ or lower is required to model VLS. However, given the sensitivity of the peak and average lateral rates of spread to the horizontal and vertical grid spacing, we suggest that a grid spacing of $30 \mathrm{~m}$ or lower is optimal for modelling VLS with WRF-Fire. Given the recent study by Mirocha et al. (2010), it would be useful to investigate the effect of varying the vertical-to-horizontal grid spacing ratio on resolving VLS. It may also be possible to use vertical stretching of the sigma vertical levels to improve computational performance.

Inclusion of the fire-to-atmosphere coupling increased the peak upslope and lateral rate of spread by maximum factors of 2.7 and 9.5 relative to the equivalent non-coupled simulation. The peak and average upslope and lateral rate of spread typically decreased as the horizontal and vertical grid spacing increased. For those coupled simulations in which VLS occurred, the laterally advancing fire fronts on the leeward slope become the dominant contributor to the power of the fire. As suggested by Sharples et al. (2012), the lateral fire spread is therefore associated with intense local pyro-convection. The tilting of the pyro-convective plume by the background winds, in addition to the highly turbulent near-fire and downwind atmospheric dynamics, provides favourable conditions for spotting downwind of the leeward slope. This supports the suggestion by Sharples et al. (2012) that extensive spotting played a critical role in the downwind extension of the active flaming region seen during VLS events in the 2003 Canberra bushfires.

The fire whirls that drive the lateral fire spread, and in some cases lead to an increase in the upslope rate of spread, have non-zero vorticity vector components along the $\hat{\boldsymbol{x}}, \hat{\boldsymbol{y}}$ and $\hat{z}$ unit vector directions, and form predominantly due to the intense pyro-convection, rather than as a feature of the terrain-modified atmospheric dynamics. The fire whirls are centred on pyro-convectively generated vertical circulations close to the fire, and can drive lateral fire spread when they cross over the lateral flank of the fire perimeter. It will be possible to reconcile the fire whirl characteristics in VLS better with current knowledge of vorticity in wildland fires (Forthofer and Goodrick, 2011) using WRF-Fire model output at sub-minute intervals, which is planned in future work.

A number of environmental conditions need to be satisfied in order for VLS to occur. Sharples et al. (2013a) demonstrated the existence of a threshold in the background wind speed for VLS using the WRF-Fire model. Sharples et al. (2012) found that there were thresholds in the terrain slope and wind direction relative to the terrain aspect for VLS events in the 2003 Canberra bushfires. Further research is needed to explore the sensitivity of VLS to additional aspects of the fire environment from within the WRF-Fire model framework, including the fuel type, the terrain slope and the background wind speed and direction. An improved understanding of these environmental thresholds will facilitate improved operational predictability of VLS. The results presented in this study ensure that WRF-Fire will be used at sufficiently high resolution in these future sensitivity studies.

WRF-Fire is one of a small number of fire spread models capable of directly modelling the two-way coupled interactions between a wildland fire and the atmosphere. This and other recent studies (Simpson et al., 2013; Sharples et al., 2013a) have shown that WRF-Fire operates at a spatial and temporal scale well suited for modelling VLS. However, WRF-Fire has several limitations that will be addressed in future work to facilitate an improved numerical investigation of VLS. For example, the semi-empirical Rothermel fire spread model (Rothermel, 1972) likely oversimplifies the dynamic interactions between the fire spread and atmosphere involved in VLS. In addition, WRF-Fire does not currently have either a spotting or crown fire model, such as those found in other fire spread models, such as FARSITE (Finney, 1998). A spotting model will be implemented in future work to investigate the apparent role of spotting in the downwind extension of the active flaming region seen in VLS events during the 2003 Canberra bushfires.

\section{The Supplement related to this article is available online at doi:10.5194/nhess-14-2359-2014-supplement.}

Acknowledgements. This research was supported by the Australian Research Council through Discovery Indigenous Award IN130100038, and was partially supported by the Australian Research Council as part of Future Fellowship FT110100576. Additional support was provided through a UNSW Canberra Silver Star Award. The work was also supported by computational resources on the Raijin supercomputer through the National Computational Merit Allocation Scheme. We acknowledge Kevin Tory, Rick McRae, Jeff Kepert, Will Thurston and Robert Fawcett for useful discussions relating to this work.

Edited by: R. Lasaponara

Reviewed by: two anonymous referees 


\section{References}

Anderson, H.: Aids to determining fuel models for estimating fire behaviour, Report, Intermountain Forest and Range Experiment Station, General Technical Report INT-122, USDA Forest Service, Ogden, 1982.

Clark, T., Jenkins, M., Coen, J., and Packham, D.: A coupled atmosphere-fire model: Convective feedback on fire-line dynamics, J. Appl. Meteorol., 35, 875-901, 1996a.

Clark, T., Jenkins, M., Coen, J., and Packham, D.: A coupled atmosphere-fire model: Role of the convective Froude number and dynamic fingering at the fireline, Int. J. Wildl. Fire, 6, 177190, 1996b.

Clark, T., Coen, J., and Latham, D.: Description of a coupled atmosphere-fire model, Int. J. Wildl. Fire, 13, 49-64, 2004.

Coen, J.: Simulation of the Big Elk Fire using coupled atmospherefire modeling, Int. J. Wildl. Fire, 14, 49-59, 2005.

Coen, J., Cameron, M., Michalakes, J., Patton, E., Riggan, P., and Yedinak, K.: WRF-Fire: Coupled weather-wildland fire modeling with the Weather Research and Forecasting model, J. Appl. Meteorol. Clim., 52, 16-38, 2013.

Countryman, C. M.: Fire whirls ... why, when, and where, Report, USDA Forest Service, Pacific Southwest Forest and Range Experiment Station, Berkeley, CA, 1971.

Countryman, C. M.: The fire environment concept, Pacific Southwest Forest and Range Experiment Station, Berkeley, California, USA, 1972.

Cunningham, P. and Linn, R.: Numerical simulations of grass fires using a coupled atmosphere-fire model: Dynamics of fire spread, J. Geophys. Res., 112, D05108, doi:10.1029/2006JD007638, 2007.

Dold, J. and Zinoviev, A.: Fire eruption through intensity and spread interaction mediated by flow attachment, Combust. Theor. Modell., 13, 763-793, 2009.

Farinha, H.: Formação de Vórtices num Incéndio Florestal - Estudo Laboratorial de um Vórtice de Eixo Horizontal e de um Tornado de Fogo, Thesis, Masters Thesis, Department of Mechanical Engineering, University of Coimbra, Portugal, 2011.

Filippi, J.-B., Bosseur, F., Mari, C., Lac, C., Moigne, P. L., Cuenot, B., Veynante, D., Cariolle, D., and Balbi, J.-H.: Coupled atmosphere-wildland fire modelling, J. Adv. Model. Earth Syst., 1, 1-9, 2009.

Filippi, J.-B., Bosseur, F., Pialat, X., Santoni, P.-A., Strada, S., and Mari, C.: Simulation of coupled fire/atmosphere interaction with the MesoNH-ForeFire models, J. Combust., 540390, doi:10.1155/2011/540390, 2011.

Finney, M.: FARSITE: Fire Area Simulator - model development and evaluation, Report, US Department of Agriculture, Forest Service, Rocky Mountain Research Station, Fort Collins, CO, 1998.

Forthofer, J. and Goodrick, S.: Review of vortices in wildland fire, J. Combust., 14, 984363, doi:10.1155/2011/984363, 2011.

Justus, C., Hargraves, W., and Yalcin, A.: Nationwide assessment of potential output from wind-powered generators, J. Appl. Meteorol., 15, 673-678, 1976.

Kirkil, G., Mirocha, J., Bou-Zeid, E., Chow, F., and Kosovic, B.: Implementation and evaluation of dynamic subfilter-scale stress models for large-eddy simulation using WRF, Mon. Weather Rev., 140, 266-284, 2012.
Klemp, J., Dudhia, J., and Hassiotis, A.: An upper gravity-wave absorbing layer for NWP applications, Mon. Weather Rev., 136, 3987-4004, 2008.

Kochanski, A., Beezley, J., Mandel, J., and Clements, C.: Air pollution forecasting by coupled atmosphere-fire model WRF and SFIRE with WRF-Chem, in: Proceedings of 4th Fire Behavior and Fuels Conference, 18-22 February 2013, Raleigh, North Carolina, USA, 2013a.

Kochanski, A., Jenkins, M., Krueger, S., Mandel, J., and Beezley, J.: Real time simulation of 2007 Santa Ana fires, Forest Ecol. Manage., 15, 136-149, 2013b.

Kochanski, A. K., Jenkins, M. A., Mandel, J., Beezley, J. D., Clements, C. B., and Krueger, S.: Evaluation of WRF-SFIRE performance with field observations from the FireFlux experiment, Geosci. Model Dev., 6, 1109-1126, doi:10.5194/gmd-61109-2013, 2013c.

Kochanski, A., Jenkins, M., Sun, R., Krueger, S., Abedi, S., and Charney, J.: The importance of low-level environmental vertical wind shear to wildfire propagation: proof of concept, J. Geophys. Res.-Atmos., 118, 8238-8252, 2013d.

Linn, R., Reisner, J., Colman, J., and Winterkamp, J.: Studying wildfire behaviour using FIRETEC, Int. J. Wildl. Fire, 11, 233246, 2002.

Linn, R., Winterkamp, J., Edminster, C., Colman, J., and Smith, W.: Coupled influences of topography and wind on wildland fire behaviour, Int. J. Wildl. Fire, 16, 183-195, 2007.

Mandel, J., Beezley, J. D., and Kochanski, A. K.: Coupled atmosphere-wildland fire modeling with WRF 3.3 and SFIRE 2011, Geosci. Model Dev., 4, 591-610, doi:10.5194/gmd4-591-2011, 2011.

Mandel, J., Amram, S., Beezley, J. D., Kelman, G., Kochanski, A. K., Kondratenko, V. Y., Lynn, B. H., Regev, B., and Vejmelka, M.: New features in WRF-SFIRE and the wildfire forecasting and danger system in Israel, Nat. Hazards Earth Syst. Sci. Discuss., 2, 1759-1797, doi:10.5194/nhessd-2-1759-2014, 2014.

McRae, R.: Breath of the dragon - observations of the January 2003 ACT Bushfires, in: Bushfire Conference 2004: Earth, Wind and Fire - Fusing the Elements, South Australian Department of Environment and Heritage, 25-28 May 2004, Adelaide, 2004.

Mirocha, J., Lundquist, J., and Kosovic, B.: Implementation of a nonlinear subfilter turbulence stress model for large-eddy simulation in the Advanced Research WRF model, Mon. Weather Rev., 138, 4212-4228, 2010.

Moeng, C., Dudhia, J., Klemp, J., and Sullivan, P.: Examining twoway grid nesting for large eddy simulation of the PBL using the WRF model, Mon. Weather Rev., 135, 2295-2311, 2007.

Peace, M. and Mills, G.: A case study of the 2007 Kangaroo Island bushfires, Report, CAWCR Technical Report No. 053, Bureau of Meteorology, Melbourne, Victoria, Australia, 2012.

Pimont, F., Dupuy, J.-L., and Linn, R.: Coupled slope and wind effects on fire spread with influences of fire size: a numerical study using FIRETEC, Int. J. Wildl. Fire, 21, 828-842, 2012.

Rothermel, R.: A mathematical model for predicting fire spread in wildland fuels, Report, Intermountain Forest and Range Experiment Station, Research Paper INT-115, Forest Service, US Department of Agriculture, USDA Forest Service, Ogden, 1972. 
Sharples, J., Viegas, D., Rossa, C., and McRae, R.: Small-scale observations of atypical fire spread caused by the interaction of wind, terrain and fire, in: VI International Conference on Forest Fire Research, edited by: Viegas, D. X., 15-18 November 2010, Coimbra, Portugal, University of Coimbra, Coimbra, 2010.

Sharples, J., McRae, R., and Wilkes, S.: Wind-terrain effects on the propagation of large wildfires in rugged terrain: fire channelling, Int. J. Wildland Fire, 21, 599-614, 2012.

Sharples, J., Simpson, C., and Evans, J.: Examination of wind speed thresholds for vorticity-driven lateral fire spread, in: 20th International Congress of Modelling and Simulation, edited by: Piantadosi, J., Anderssen, R., and Boland, J., http://www.mssanz.org. au/modsim2013/A3/sharples3.pdf (last access: 25 August 2014), 2013a.

Sharples, J., Towers, I., Wheeler, G., Wheeler, V.-M., and McCoy, J.: Modelling fire line merging using plane curvature flow, in: 20th International Congress on Modelling and Simulation, edited by: Piantadosi, J., Anderssen, R., and Boland, J., http:// www.mssanz.org.au/modsim2013/A3/sharples2.pdf (last access: 25 August 2014), 2013b.

Simpson, C., Sharples, J., Evans, J., and McCabe, M.: Large eddy simulation of atypical wildland fire spread on leeward slopes, Int. J. Wildl. Fire, 22, 282-296, 2013.
Skamarock, W., Klemp, J., Dudhia, J., Gill, D., Barker, D., Duda, M., Huang, X.-Y., Wang, W., and Powers, J.: A description of the Advanced Research WRF Version 3, Report, NCAR, http: //www2.mmm.ucar.edu/wrf/users/docs/arw_v3.pdf (last access: 25 August 2014), 2008.

Sullivan, A.: Wildland surface fire spread modelling, 1990-2007. 1: physical and quasi-physical models, Int. J. Wildl. Fire, 18, 349-368, 2009a.

Sullivan, A.: Wildland surface fire spread modelling, 1990-2007. 2: empirical and quasi-empirical models, Int. J. Wildl. Fire, 18, 369-386, 2009b.

Sullivan, A.: Wildland surface fire spread modelling, 19902007. 3: simulation and mathematical analogue models, Int. J. Wildl.Fire, 18, 387-403, 2009c.

Viegas, D. X., Raposo, J. R., Davim, D. A., and Rossa, C. G.: Study of the jump fire produced by the interaction of two oblique fire fronts. Part I: analytical model and validation with no-slope laboratory experiments, Int. J. Wildl. Fire, 21, 843-856, 2012.

Viegas, D. X. and Pita, L. P.: Fire spread in canyons, Int. J. Wildl. Fire, 13, 253-274, 2004.

Weise, D. and Biging, G.: A qualitative comparison of fire spread models incorporating wind and slope effects, Forest Science, 43, 170-180, 1997. 